\title{
Determination of 12 acrylate compounds in plastic food contact materials via high performance liquid chromatography
}

\author{
Yue Qiu ${ }^{1 *}$, Qing Zhang ${ }^{1}$, Genrong Li $^{1}$, Mei Long ${ }^{1}$ and Dong Xiang ${ }^{1}$ \\ ${ }^{1}$ Chongqing Academy of Metrology and Quality Inspection, 401123 Chongqing, China.
}

\begin{abstract}
A high performance liquid chromatography (HPLC) method was used to determine 12 acrylate compounds in plastic food contact materials. The plastic food contact material samples were extracted by ultrasonic with methanol. The mixed solution of water and acetonitrile was used as mobile phase for gradient elution. The samples were separated by ZORBAX SB-AQ column $(250 \mathrm{~mm} \times 4.6 \mathrm{~mm}, 5 \mu \mathrm{m})$, and analyzed by diode array detector (DAD). The results showed that under the optimal chromatographic conditions, the 12 acrylate compounds had good linear relationships in the range of $0.01-10.0 \mathrm{mg} / \mathrm{L}$, the correlation coefficient of the standard curves were higher than 0.999 , and the detection limits (LODs) were $0.03-0.08 \mathrm{mg} / \mathrm{kg}$. The recovery rate was between $85.4 \%$ and $110.7 \%$, and the relative standard deviation was from $1.6 \%$ to $5.2 \%$. The method was simple and accurate, and can be used for the analysis and detection of 12 acrylate compounds in plastic food contact materials.
\end{abstract}

\section{Introduction}

Acrylate compounds are the general term of esters of acrylic acid and its homologues, which are an important chemical raw material mainly used for the production of adhesives, synthetic resins, rubber and plastics [1-3]. Acrylate compounds have anesthetic effect, obvious stimulation and sensitization effect on the skin. Oral administration will strongly stimulate the oral cavity and digestive tract, which may cause dizziness, dyspnea and neuroticism $[4,5]$. In the process of using, harmful substances in plastic food contact materials will be transported into the human body through food. The national standard GB/T 9685-2016 has made clear provisions on the specific migration amount of various acrylates and methacrylates [6], but there is still no relevant standard for detecting acrylates and acrylates monomers in food contact materials in China.

At present, the main methods for the determination of acrylate compounds include gas chromatography [7], gas chromatography-mass spectrometry [8], high performance liquid chromatography [9], etc. These methods are mainly used for quantitative analysis of a single or a few acrylate compounds. Due to the low boiling point and high volatility of acrylates, it is easy to produce self-polymerization reaction at high temperature. Therefore, it is difficult to achieve the ideal peak shape and recovery rate of acrylate compounds by gas chromatography or gas chromatography-mass spectrometry.

In this paper, a high performance liquid chromatography (HPLC) method was used to analyze and detect 12 acrylate compounds in plastic food contact materials, which can avoid the influence of high temperature on target substances in gas chromatography. This method is simple, accurate and reliable, and can provide technical support for the detection of acrylate compounds in plastic food contact materials in the future.

\section{Materials and methods}

\subsection{Materials and reagents}

12 acrylate standards were all supplied from Dr. Ehrenstorfer (Augsburg, Germany). HPLC grade acetonitrile was purchased from Merck (Darmstadt, Germany). The water used in the experiment was ultrapure water.

\subsection{Instruments and equipment}

Agilent 1260 high performance liquid chromatograph (with DAD detector), Agilent, USA; SQP Electronic analytical balance, Sedris, Germany; Bilon-2000 CT ultrasonic cleaner, Shanghai Bilang Instrument Co., LTD.

\subsection{Methods}

\subsubsection{Preparation of standard solution}

The standard substance of $25.0 \mathrm{mg}$ was accurately weighed to volumetric flask of $25 \mathrm{~mL}$, then dissolved and volume-stabilized with methanol to prepare a standard solution $(1000 \mathrm{mg} / \mathrm{L})$. The mixed standard working solutions of $0.1 \mathrm{mg} / \mathrm{L}, 0.5 \mathrm{mg} / \mathrm{L}, 1.0 \mathrm{mg} / \mathrm{L}, 5.0$

*orresponding author: qiuyuecqu@163.com 
$\mathrm{mg} / \mathrm{L}$ and $10.0 \mathrm{mg} / \mathrm{L}$ were prepared with methanol by step dilution method for HPLC analysis.

\subsubsection{Sample pretreatment}

The typical samples of $2 \mathrm{~g}$ were weighed and cut into small pieces with an area of no more than $5 \mathrm{~mm} \times 5 \mathrm{~mm}$, and mixed evenly. The $0.5 \mathrm{~g}$ sample was accurately weighed into a $25 \mathrm{~mL}$ colorimetric tube, and $10 \mathrm{~mL}$ methanol was added for ultrasonic extraction at room temperature for $30 \mathrm{~min}$. The supernatant was taken through $0.45 \mu \mathrm{m}$ organic filtration membrane for UPLC analysis.

\subsubsection{Chromatographic condition}

A ZORBAX SB-AQ column $(250 \mathrm{~mm} \times 4.6 \mathrm{~mm}, 5 \mu \mathrm{m})$ was used to analysis. The mobile phase A was water and the mobile phase $\mathrm{B}$ acetonitrile. The column temperature was $40^{\circ} \mathrm{C}$, the injection volume was $20 \mu \mathrm{L}$, the detection wavelength was $210 \mathrm{~nm}$, and the flow rate was 1.0 $\mathrm{mL} / \mathrm{min}$. Gradient elution procedure: 0-6.5 min, 20\%$40 \% \mathrm{~B} ; \quad 6.5-17 \mathrm{~min}, \quad 40 \%-65 \% \mathrm{~B} ; \quad 17-17.2 \mathrm{~min}$, $65 \% \sim 100 \% \mathrm{~B} ; 22-22.2 \mathrm{~min}, 100 \%-20 \% \mathrm{~B}$, then kept for 6 $\min$.

\section{Result and analysis}

\subsection{Selection of chromatographic conditions}

The effect of chromatographic column on the separation of acrylate compounds was investigated. It was found that ZORBAX SB-AQ column had the best separation effect on 12 target compounds, so this column was selected for subsequent experiments.

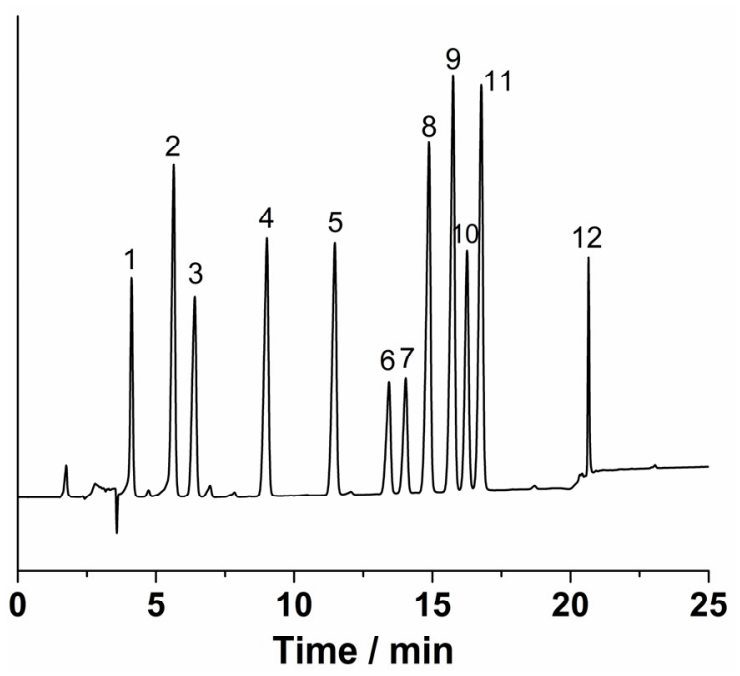

Fig. 1. Chromatogram of standard solution of 12 acrylate compounds (the peak numbers were the same as table 1)

Due to the weak polarity of acrylate compounds, the peak time in reversed-phase column was not too fast, and there was no need to add acid and salt in the mobile phase. Therefore, acetonitrile-water system was more suitable. The maximum ultraviolet absorption of acrylates compounds was around $210 \mathrm{~nm}$, therefore 210 $\mathrm{nm}$ was selected as the best measurement wavelength. Under the optimal conditions, 12 acrylate compounds were able to achieve better baseline separation, and the chromatogram was shown in Figure 1.

\subsection{Standard curve and detection limit}

According to the working conditions of the instrument, the mixed standard solution series was determined, and the mass concentration of each compound was linearly regressed by the peak area of each compound. The results showed that the mass concentrations of the 12 acrylate compounds were linear in the range of 0.1-10 $\mathrm{mg} / \mathrm{L}$, and the correlation coefficient were more than 0.999 . The detection limit of the method was calculated by 3 times signal-to-noise ratio $(\mathrm{S} / \mathrm{N} \geqslant 3)$, and the method verification results were shown in Table 1.

Table 1. Linear equation, correlation coefficient $\left(\mathrm{R}^{2}\right)$, and determination limit (LOD) of 12 acrylate compounds.

\begin{tabular}{|c|c|c|c|c|}
\hline No. & Compound & Linear equation & $\mathbf{R}^{2}$ & $\begin{array}{c}\text { LOD } \\
(\mathrm{mg} / \mathrm{kg})\end{array}$ \\
\hline 1 & $\begin{array}{l}\text { acrylic acid-2- } \\
\text { hydroxyethyl } \\
\text { ester }\end{array}$ & $y=36.9 x+1.22$ & 0.9993 & 0.08 \\
\hline 2 & $\begin{array}{l}\text { 2-hydroxyethyl- } \\
\text { 2-methyl-2- } \\
\text { acrylate }\end{array}$ & $y=81.3 x+2.54$ & 0.9995 & 0.03 \\
\hline 3 & methyl acrylate & $y=61.8 x+1.95$ & 0.9993 & 0.03 \\
\hline 4 & $\begin{array}{l}\text { methyl methacry } \\
\text { late }\end{array}$ & $y=81.5 x+2.53$ & 0.9993 & 0.03 \\
\hline 5 & $\begin{array}{c}\text { ethyl methacrylat } \\
\mathrm{e}\end{array}$ & $y=79.2 x+4.46$ & 0.9993 & 0.03 \\
\hline 6 & $\begin{array}{l}\text { 2-acrylate-1,1- } \\
\text { dimethylethyl } \\
\text { ester }\end{array}$ & $y=34.2 x+0.61$ & 0.9993 & 0.08 \\
\hline 7 & n-butyl acrylate & $y=33.2 x+0.76$ & 0.9993 & 0.08 \\
\hline 8 & phenyl acrylate & $y=98.2 x+3.27$ & 0.9994 & 0.03 \\
\hline 9 & $\begin{array}{c}\text { phenyl } \\
\text { methacrylate }\end{array}$ & $y=117.7 x+3.76$ & 0.9993 & 0.03 \\
\hline 10 & $\begin{array}{c}\text { butyl methacryla } \\
\text { te }\end{array}$ & $y=63.3 x+5.01$ & 0.9991 & 0.03 \\
\hline 11 & $\begin{array}{c}\text { phenyl } \\
\text { methacrylate }\end{array}$ & $y=103.2 x+5.73$ & 0.9993 & 0.03 \\
\hline 12 & 2-octyl acrylate & $y=21.8 x+0.87$ & 0.9997 & 0.08 \\
\hline
\end{tabular}

\subsection{Precision and recovery}

Blank plastic food contact material samples were selected for standard recovery and precision testing, with the standard level of $0.1,1.0$ and $10.0 \mathrm{mg} / \mathrm{L}$, respectively, and each concentration level was repeated for 6 times. The experimental results (Table 2) showed that the recoveries (R) of 12 acrylate compounds were in the range of $85.4 \%-110.7 \%$ and the relative standard deviation (RSD) was $1.6 \%-5.2 \%$ at the three standard 
levels, which could meet the actual detection requirements.

Table 2. Recoveries and RSDs ( $n=6$ ) for acrylate compounds

\begin{tabular}{|c|c|c|c|c|c|c|c|}
\hline \multirow[b]{2}{*}{ No. } & \multirow{2}{*}{ Com-pound } & \multicolumn{2}{|c|}{$0.1 \mathrm{mg} / \mathrm{kg}$} & \multicolumn{2}{|c|}{$1.0 \mathrm{mg} / \mathrm{kg}$} & \multicolumn{2}{|c|}{$10.0 \mathrm{mg} / \mathrm{kg}$} \\
\hline & & $\mathrm{R} / \%$ & $\begin{array}{c}\text { RSD } \\
/ \%\end{array}$ & $\mathrm{R} / \%$ & $\begin{array}{c}\text { RSD/ } \\
\%\end{array}$ & $\mathrm{R} / \%$ & $\begin{array}{c}\text { RSD } \\
/ \%\end{array}$ \\
\hline 1 & $\begin{array}{l}\text { acrylic acid-2- } \\
\text { hydroxyethyl } \\
\text { ester }\end{array}$ & 90.5 & 3.8 & 94.2 & 2.1 & 98.4 & 1.9 \\
\hline 2 & $\begin{array}{l}\text { 2-hydroxyethyl- } \\
\text { 2-methyl-2- } \\
\text { acrylate }\end{array}$ & 88.3 & 3.1 & 97.1 & 3.3 & 99.7 & 2.5 \\
\hline 3 & methyl acrylate & 91.0 & 2.7 & 104.9 & 2.0 & 103.4 & 2.1 \\
\hline 4 & $\begin{array}{l}\text { methyl methacryl } \\
\text { ate }\end{array}$ & 108.6 & 4.6 & 90.3 & 3.8 & 101.2 & 2.7 \\
\hline 5 & $\begin{array}{c}\text { ethyl methacrylat } \\
\mathrm{e}\end{array}$ & 87.9 & 2.5 & 103.2 & 2.3 & 100.9 & 1.8 \\
\hline 6 & $\begin{array}{l}\text { 2-acrylate -1, 1- } \\
\text { dimethylethyl } \\
\text { ester }\end{array}$ & 110.7 & 3.1 & 106.6 & 2.6 & 94.3 & 1.9 \\
\hline 7 & n-butyl acrylate & 85.4 & 5.2 & 92.1 & 3.7 & 98.6 & 2.3 \\
\hline 8 & phenyl acrylate & 107.7 & 4.7 & 103.7 & 3.6 & 104.5 & 2.4 \\
\hline 9 & $\begin{array}{c}\text { phenyl } \\
\text { methacrylate }\end{array}$ & 106.4 & 4.0 & 94.9 & 2.9 & 96.7 & 2.7 \\
\hline 10 & $\begin{array}{c}\text { butyl methacrylat } \\
\mathrm{e}\end{array}$ & 92.3 & 2.4 & 97.8 & 2.0 & 101.1 & 1.9 \\
\hline 11 & $\begin{array}{c}\text { phenyl } \\
\text { methacrylate }\end{array}$ & 93.5 & 3.6 & 90.5 & 3.3 & 104.2 & 1.6 \\
\hline 12 & 2-octyl acrylate & 90.8 & 4.2 & 102.9 & 3.4 & 99.6 & 2.5 \\
\hline
\end{tabular}

\subsection{Actual sample test}

Plastic food contact materials with different materials (PE, PC, PET, etc.) were selected for actual sample analysis, and 20 actual samples were detected by this method. The results showed that a certain amount of acrylate compounds residue was detected in two samples. Sample 1 contained methyl methacrylate, phenyl methacrylate and 2-octyl methacrylate, and sample 2 contained ethyl methacrylate and phenyl methacrylate at contents ranging from $1.40-3.41 \mathrm{mg} / \mathrm{kg}$, and the contents of each substance were listed in Table 3. 
Table 3. Average contents $(\mathrm{mg} / \mathrm{kg})$ of acrylate compounds in commercial samples

\begin{tabular}{|c|c|c|c|}
\hline No. & Compound & Sample 1 & Sample 2 \\
\hline 1 & $\begin{array}{l}\text { acrylic acid-2- } \\
\text { hydroxyethyl ester }\end{array}$ & - & - \\
\hline 2 & $\begin{array}{l}\text { 2-hydroxyethyl-2- } \\
\text { methyl-2-acrylate }\end{array}$ & - & - \\
\hline 3 & methyl acrylate & 2.31 & - \\
\hline 4 & methyl methacrylate & - & - \\
\hline 5 & ethyl methacrylate & - & 2.06 \\
\hline 6 & $\begin{array}{c}\text { 2-acrylate-1,1 } \\
\text { dimethylethyl ester }\end{array}$ & - & - \\
\hline 7 & n-butyl acrylate & - & - \\
\hline 8 & phenyl acrylate & 一 & - \\
\hline 9 & phenyl methacrylate & - & - \\
\hline 10 & butyl methacrylate & - & - \\
\hline 11 & phenyl methacrylate & 3.20 & 3.41 \\
\hline 12 & 2-octyl acrylate & 1.40 & - \\
\hline
\end{tabular}

"- " related to below the limit of detection

\section{Conclusions}

In this study, a HPLC method for the determination of 12 acrylate compounds in plastic food contact materials was established by investigating and optimizing the chromatographic conditions. This method could realize the effective separation of 12 acrylate compounds, and the detection limit, standard recovery and precision could meet the requirements of actual samples. This method was easy to operate, sensitive and accurate, and could provide a new technical reference for the analysis and detection of acrylate compounds in plastic food contact materials in the future.

\section{Funding}

This research was funded by Scientific Research Project of Chongqing Market Supervision Administration [CQSJKJ2019005].

\section{References}

1. H.Y. Zhao, G.F. Cao, X.L. Zhang, et al., Phys. Test Chem. Anal. Part B: Chem. Anal. 45, 6 (2009)

2. Z. Wei, H. Huang, Chem. Bioeng. 26, 8 (2009)

3. X.Y. Sengtu, W. Zhang, Dye. Finish. 34, 5 (2008)

4. S.G Gong, B. Kong, S.X. Tuo, et al., Chin. J. Chromatogr. 31, 10 (2013)

5. D. Liu, X.Q. Chen, M.J. Wu, et al., Chin. J. Chromatogr. 29, 12 (2011)

6. GB 9685-2008 Hygienic standards for uses of additives in food containers and packaging materials [S].

7. W.L. Hu, M. Pang, L. Li, et al., Phys. Test Chem. Anal. Part B: Chem. Anal. 49, 2 (2013)

8. X.L. Dai, D. Li, X.L. Chen, et al., Admin. Tech. Environ. Monitor. 24, 5 (2012)

9. Y. Zuo, D.Z. Sun, C. Luo, et al., Phys. Test Chem. Anals. Part B: Chem. Anal. 51, 2 (2015) 